\title{
CLINICAL
}

\section{"IRRECONCILABLE DIFFERENCES" BETWEEN PARENT AND CHILD: \\ A Case Report of Interactional Pathology}

\author{
Kay M. Tooley, Ph.D.
}

Department of Psychiatry, University of Michigan Medical Center, Ann Arbor

Certain parents use their child as a representative of their own unacceptable impulses, perceiving the youngster as evil and seeking experts to confirm their opinion. They come to mental health clinics for diagnoses but not treatment; evidence that contradicts their view is ignored out of a need to protect their own precarious psychological balance. The child, in spite of good early adjustment, tends to conform to the parents' preferred perception. Legal and ethical implications for professionals working with such cases are discussed.

$T^{T}$ here has been a recent shift in diagnostic emphasis from a consideration of individual psychopathology to a consideration of the field forces operant within a family. We are increasingly confronted with evidence that the child is far from "formed" by age five: that much symptomatic behavior, rather than historically and intrapsychically determined, is reactive to current pressure, strain, and family mythology. Family interactions are often subtle and easily underestimated but the dividends in economy and effectiveness of treatment justify the effort required to investigate them.

It is the growing conviction of this author that individually-focused child therapy may fall short of the successful outcome we desire, not because historical traumata are insufficiently dealt with or because the method is inadequate but because the current family pressures work to continue the behavior and selfpercepts we are attempting to modify in individual treatment. Even when parents are involved in concurrent case work, the subtle, unconscious operations of 
family pathology may not be visible unless the group interaction itself is observed. Ackerman ${ }^{2}$ was the first to insist that children cannot be properly evaluated outside of a family and social context. Henry ${ }^{5}$ has contributed vivid observations of families in interaction, of psychopathology in statu nascendi. Bermann ${ }^{3}$ has drawn a careful, detailed and tragic portrait of a family coping with stress, fending off breakdown by means of the sacrifice of one of its child members. Families are complex organizations whose members have a joint, as well as individual unconscious, and symbolic nonverbal communication patterns that accompany and support an unrelenting schooling of each member as to what he "is" and "will be."

Recognition of a particular pathological family interaction can escape ordinary diagnostic screening measures because the focusing of pathology on one individual member may improve functioning and relieve conflicts in other members of the family. This is highly likely to be true of scapegoat children, if the literature we have is correct in its conclusions, because the selection of a scapegoat in itself works to alleviate psychic distress and conflict in the rest of the family group. One can then expect that the family will resist efforts to change the pain-alleviating arrangement, very often by withdrawing the child from treatment.

We have seen scapegoat children who functioned to relieve their mothers of guilt related to the loss of another child under particularly narcissistically-damaging circumstances (severe mental retartardation requiring hospitalization, sudden infant death, death from a congenital defect). Years after the trauma, mother and scapegoat child are locked in a bitter sado-masochistic struggle alleviated by the extrusion of the child from the home. ${ }^{9}$ Bermann's family was coping with current as well as past stress in their use of a scapegoat child. ${ }^{3}$ Johnson and Szurek ${ }^{6}$ have described parents' use of a child as a vehicle for acting out their own forbidden, unconscious wishes to the child's detriment.

All of these "solutions" neglect the reality of the child's self in favor of what the parents need him to "be." They are screens upon which parents have focused their projections of unacceptable components of the parent's self. Clinicians then universally share Bermann's painful impotence: able to foresee with great clarity the child's inevitable destruction and often quite unable to do anything about it. One may take personal and professional comfort from the belief that the accumulation of data, while not maximally usable at present, may contribute to a future mastery, a new technique, or a change in legal policy.

\section{THE FAMILY "PROBLEM"}

This report offers a description of a family pathology that is vivid in its extremity but that was observable in five other cases in less extreme form. These families utilize a child to fend off a psychotic dissolution. Oral, anal, and genital sins, insanity and mental retardation, moral corruption, satanic deviousness, and murderous impulses are "seen" in the child by the parents, often to the utter bewilderment of the outsider. They are brought to mental health settings by parents who recite lists of their peculiar behavior with great distress, begging us "not to be taken in" by the child, and requesting help. What becomes evident is that they are desperately seeking a confirmation of their perception of the 
child, an "expert" who will agree with them. If this is not forthcoming they seek another expert who can "understand" the problem.

Histories of such children are replete with brief diagnostic contacts with many agencies and a few abortive therapeutic contacts. Bizarre, psychotic material usually is not evident in interviews with the parents, only in observed interactions or self-descriptions of interactions with their child. The role of the child in maintaining parental stability is inferable from the fact that the child's history and behavior is usually the only thing the parents will discuss. We were often surprised in retrospect that we knew very little of the parents' personal history after several contacts. Their obsession with the child's evil fills much of their lives.

This was clearly operant with the $M$. family. Ruthie's parents talked about her with each other, secretly observed her in solitary play for long periods of time while taking notes, spent hours beseeching her not to be "bad," and involved her in written confessions of evil impulses and actions. She filled their lives and thoughts, keeping any other concerns out of consciousness. Mr. and Mrs. $M$. vacillated between presenting her for residential treatment (which would have comfortingly confirmed their perception of her) and withdrawing her from treatment (because they could not function with her away). Becoming aware of this, we felt that the only way to intervene with the $M$. family would be to have Ruthie made a ward of the court. The parents resisted, and the court-dealing daily with battered children with fractured skulls, broken legs, and ruptured spleens-was unimpressed with our argument. Other social agencies were worried about Ruthie also: The public school at the time of the first contact, and Protective Services later. They also were unsuccessful in efforts to intervene. The circumstances gave us the rare opportunity to observe a family over time and to assess the impact on the child of the parental projection. The family's pathology successfully maintained distance from all outside efforts to influence it and ran its course, uninterrupted.

\section{Mr. and Mrs. $M$.}

Mr. and Mrs. $M$. brought their eightyear-old adopted daughter, Ruthie, to the hospital for an evaluation. She had been referred by a local psychiatric consultant for inpatient treatment. The $M$.s had adopted Ruthie at age four when her natural mother found herself unable to care for the family. The $M$.s were in their fifties at the time of the adoption and unable to give any reason for assuming the responsibility for the upbringing of a young child other than the altruistic one of "rescuing" her from what they saw as a degenerate, immoral, and impoverished home situation.

They reported considerable difficulty with Ruthie ever since, had sought professional help for, variously, her "mental retardation," her "brain damage," and her "emotional disturbance." They described her as intellectually slow, as incontinent ("She wets her pants in school every day."); they were very distressed by her "lying and stealing," by her cruelty to animals, by her resistance to socialization (e.g., table manners, cleanliness). They worried because she "got lost on the way home from school every day." They were most distressed 
by the public school's refusal to recognize Ruthie's problems and to place her in a special education classroom. Indeed, they felt that they had not been "helped" by any of the professionals they had consulted; they expressed sadness, weariness, and discouragement.

They were considered generally to be well intentioned, concerned people deeply interested in their child, if a little fussy, overprotective, and rigid. It was noted, fleetingly, that Mr. $M$. was bombastic, litigious, and deeply suspicious of the world outside his home fortress; that Mrs. $M$. was vague, unfocused, and oddly childish. No one, however, saw any evidence of bizarreness or thought disorder in either parent. (There was little opportunity to explore the possibility; we had all been equally unsuccessful in eliciting any data that did not focus on Ruthie.)

With the M.s reluctant consent, we contacted the home school system for information. Their information provided a stunning contrast to that provided by the M.s. Their folder contained the laborious documentation, the letters in triplicate, the memos of the content of meetings, that characterize a school system reluctantly and cautiously preparing to go to court. Ruthie was "truant." She had been withheld from school for better than $50 \%$ of the attendance year, not only for the current year but in what could be determined of her school past.* Bureaucracies are cumbersome. After an initial inquiry to ascertain whether Ruthie was in fact enrolled elsewhere after withdrawal, the home school did not pursue the matter. The receiving schools did not report her new withdrawal.

Ruthie had fallen between the cracks of bureaucratic assumptions and definitions of responsibility. She was now eight, and to our astonishment was working at grade level in spite of her poor attendance. By the school's report she was "well accepted by teachers and children in spite of her rare attendance and 'unusual clothing'." There are reports of group and individual IQ tests that indicated intelligence in the high average range, as well as achievement tests that supported the school's claim of age-adequate mastery of basic skills. It was clear, in spite of the tone of careful, pained courtesy the school maintained, that they thought Ruthie's only serious problem was her parents.

\section{The Parents' "Case"}

Mr. and Mrs. M. presented a sheaf of notes and signed "confessions" to rebut the school's description of Ruthie. Often naive, more than a little bizarre, frequently bombastic and legalistic, it presented a chilling picture of family interaction.

Mr. $M$., in careful, amateurish legalese, reasoned away the school's complaints. Ruthie was not peculiarly dressed, he said, showing us a letter with two carbons to the school system:

... research undertaken by myself among sellers of clothing in this area confirm that many such shoe-boots are sold, although more

\footnotetext{
* The difficulty of such determination should not be underestimated. Parents who are intent on evading school attendance can move to nearby school districts, falsely report school attendance at a religious school or placement in a residential treatment center without reporting withdrawal a few weeks later. They can comply for a few weeks with the complaining school system. They can report frequent illnsss in the child that necessitated her being kept from school. The $M . s$ did all of the above.
} 
to boys than girls. Please feel free to contact Mr. G. C.- of Variety Store, Green Streetfor corroboration. Please advise forthwith wherein such clothing is inappropriate. .

To the school's assertion that Ruthie functioned well and happily in school and never wet her pants, Mr. $M$. wrote:

Item: Ruthie is supplied each morning with clean underwear by her mother, a most fastidious woman. Item: She is dirty and has wet herself when she comes home at night. It is logical to conclude that she wets herself at school.

To this document the parents attached a "Confession dictated to her Parents and signed by Ruthie," submitted as conclusive proof of either the school's mendacity or gullibility: "Mother, one day I even squatted on the classroom floor and piddled."

Mr. and Mrs. $M$. provided a diary of anecdotal observations often countersigned and "witnessed" by themselves or Ruthie:

Mother, please don't ever let me handle the bird because my hands are too strong and I might kill the bird [pet parakeet]. I love the bird very much momy [sic] and I never know what I'm doing. Dictated by Ruthie, signed the mother.

My name is firebug because I started many, many fires . . . my momy and daddy are sweet to me but I never mind them, I want to be beautiful like my momy is. Dictated by Ruthie, signed the mother.

The diary continued with cautions about flattering Ruthie, bribing her, or being taken in by her ability to

. . put on charm, be a sweet girl. It is difficult to get the truth out of her for quite some time until under pressure she finally tells the truth .... she is cunning.

They offered testimony also about the school:
She regresses whenever she goes back to school, she's easily upset emotionally as for example she said children jeer and make fun of her. This is one of the reasons she does not want to go to school. "They call me retarded when I'm not," so she says. [In Ruthie's writing:] Abcut school, I want to learn but I'm crowded at public schools. The teacher bribes me all the time. I am a bad girl when I go there but when I'm with my momy I'm trying to improve.

There followed "documentations," signed and countersigned, of her indifference in the performance of household chores, the dropping of clothes in her bedroom, her reluctance to bathe, and "the putting of detergent in the coffee pot thus making the father very ill."

There was finally an "Addendum from The Mother," entitled "Hurting and Molesting of the Birds":

Incident: About two weeks ago she began mimicking a parrot talking and whistling. She appeared to be a ventriloquist and fooled both my husband and myself because we really thought the parrot was talking. But when viewed from a distance in a dark bedroom we could see her in the kitchen and noticed the muscles in her neck and mouth. It was during this time the parrot supposedly said some very vulgar and vile words.

The preceding record is quoted in some detail because it gives by far the most disturbing picture of the parentchild interaction. However, the family was intermittently in touch with us for six years and the "anecdotal record" quoted above provided the most accurate basis for diagnosis and prediction.

\section{Ruthie}

The focus of the intramural warfare summarized above proved to be a gangly and engaging eight-year-old. Both interviewer and examiner noticed the contrast between her determinedly babyish 
presentation of herself while with her parents and her age-appropriate behavior away from them. At first meeting, she was crooning and talking baby talk to a Raggedy Ann doll she had picked up in the lobby. When her mother urged her to go with the examiner, clearly implying that she was shy and afraid, Ruthie coyly begged to be able to "take her baby with her," hugging the doll to herself. Her "baby" was casually tucked under her elbow when she got on the elevator and tossed onto a table when she entered the office, to be carefully reclaimed after two hours for her trip back to her parents.

She was dressed in a frilly, bedraggled party dress. Heavy, wrinkled, baggy tights covered a long expanse of leg ending in the very substantial shoe-boots that had figured in the school correspondence about peculiar dress. No one item was unequivocally inappropriate but the combination was peculiar and suggested a late-latency child masquerading as a five-year-old. Both interview and test conclusions stressed Ruthie's capacity for shrewd and accurate reality testing, excellent social perception and sturdy ego skills-"a very intact personality."

She clearly perceived her relationship with the $M . s$ as tenuous, thought that she had been fortunate to be adopted, and was willing to do whatever was required of her to maintain her place with them. She perceived their need to displace difficulties onto her, and she fervently encouraged the battle with the school system. We were somewhat puzzled by this, and finally decided that by means of it she was able to maintain an affectionate alliance with her parents against the malevolent outsider, the school.
At this age, Ruthie saw her "badness" somewhat as other children might view their vaccination sore, their broken-arm cast, or their cough-an "unpleasure" surely, but a mark of distinction, the source of considerable cozy parental concern, and the occasion of much parading before strange adult professionals. It was not a part of her perception of herself. Her "badness" totally absorbed her parents, thus making her central and important to the family. There was only a slight hint in the psychological testing, quickly and anxiously repudiated, of resentment of this state of affairs. "Why does it always have to be me?" She was showing signs of trying to make herself impervious to hurt, of a need to fend off an introjection of a bad self-percept. Human percepts were changed to stone, to statues, and finally to statues that wept (and leaked water in other ways). The early testing warned that Ruthie's sturdy ego was under seige, and that the first casualty might be her capacity for warm and satisfying obiect relations. There was depressive material present, a sense of imminent abandonment, rejection and unprotected aloneness, perhaps resulting from her early separation from her natural family but certainly sustained by her current life situation.

Ruthie felt that growing up, with what it implied of autonomy, ability, and sexuality, could shatter her fragile security; she consciously adopted a stance that encouraged her parents to believe that nothing could be further from her wish or competence. What was surprising was her ability to split the school world from the home world. According to the school principal, she

... appears happy, is attentive, cooperative, and applies herself diligently to her studies. 
She participates in classroom discussion and volunteers for assignments.

In this capacity for adapting well to and garnering self-esteem nourishment from the world away from home, she reminded us of other scapegoat children we have treated. ${ }^{9}$ It seems that, with a little bit of luck and a different placement, Ruthie might have become one of that large sample of children cited often by our social critics-children who transcend a difficult early environment to functiton well and happily.

\section{Ruthie Five Years Later}

After our first contact, the M.s had angrily withdrawn Ruthie from our consideration following our unsuccessful support of court wardship to insure uninterrupted treatment. After successfully opposing the ward of the court proposal, the parents quieted the school system by placing Ruthie in a private psychiatric hospital from which they withdrew her six weeks later. The school system, unaware for several months that she was home again, sighed wearily and began another truancy petition. The $M$.s, in answer, began negotiations to admit Ruthie to a state hospital. They were successful in having her accepted for admission, told stories to Ruthie about attendants beating and killing patients in state hospitals, and "out of anguish for her well-being" changed their minds prior to admission. Aside from these attempts, we were aware, over the next four years, of the family's further peregrinations through requests for records from children's hospitals, private schools, mental health clinics. The pattern persisted: presentation for evaluation, and withdrawal at the prospect of separation or treatment.
We renewed our contact at the behest of Protective Services in Ruthie's home city five years after the initial contact. Protective Services reported that

. . Ruthie was locked in her room every night, that she had to go to the bathroom in a pail in her room, that she was not allowed to be out of the house except to go to school whcih was infrequently. She stayed in her room for all of her out of school hours. She was allowed only two sets of clothes. Her mother called any friends she made at school and told them to drop her. A male boarder in the M.'s home verified he was encouraged to use a strap on Ruthie for bad behavior and the strap was frequently used. She was made to eat her meals from a tray on the floor and was occasionally deprived of meals for extensive periods.

The $M$.s had calmly affirmed and calmly defended what they saw as necessary discipline. They presented their old list of wrongdoings as currently true, having added that after she started having periods she refused to wear either sanitary napkins or underwear. Ruthie claims she was not allowed to have sanitary napkins, that her parents refused to believe she was menstruating when she was. Ruthie was living in a group home awaiting court disposition, and the home reported no observation of any bizarre behavior beyond a modicum of young adolescent testing of limits.

Under court order, the $M$.s reappeared at the hospital with Ruthie. Their anger at us had been forgotten in the excitement of the intervening five years and in the bouyant hope that this time they "would get a good doctor who could understand the problem."

\section{Ruthie, Age 13}

The reevaluation, occurring as it did with the prospect of a court action imminent, involved explaining to Ruthie 
the purpose of the evaluation-who would see it and the uses to which it would be put. Consequently, she was very properly cautious in her communication. The sturdy ego we had noted before implemented a tight, well-guarded interview and testing performance. She delivered a "press release" about how her parents must be good parents since they took her on trips and beggared themselves for her. If the judge put her in an institution, her parents were going to move to California, and any parents were better than no parents, weren't they?

Projective testing revealed some ominous changes:

Ruthie is now strongly divided in her perception of herself. She perceives herself as a bad, ugly, hateful girl who needs to be punished. If someone else is sick or upset she must have done something wrong, it must be her fault. When the feeling of self-hatred becomes strong, Ruthie is tempted with thoughts of killing herself ... one prominent means she uses to cope with her depression and selfhatred is oppositional "naughty" behavior. By means of it she incurs the punishment she feels she deserves.

The report noted the long-range as well as the immediate danger of this pattern. The more punishment, the greater the anger and self-hatred. On the other hand, placement at this time in a benign, nonpunitive environment would leave Ruthie with no relief from the now internalized self-hatred. She might well be impelled to "sexual misbehavior or more extreme forms of provocation as she enters adolescence." The evaluation recommended placement with psychotherapy available, the latter necessary to forestall Ruthie's need to punish herself if the environment did not confirm her view of herself as hateful.

The healthy core of her personality was now much diminished but not gone. There was a small but present sense that maybe everything that went wrong in the world was not her fault after allthat it wasn't all wrong to want friends, to like dancing, to enjoy TV, and to flirt with boys.

More prominent were convictions that sexually mature females are unacceptable. Men do bad things to women; sexuality was confused with beatings or physical harm. Ruthie was now avoidant of any close relationships, convinced that if she liked someone, trusted someone, confided in someone, then someone would use the intimacy of the relationship to hurt her. Closeness meant only that she was an easier target for both physical and psychological attack.

In the meantime, Ruthie was living in the group home and the $M$.s were visiting her there. They announced their intention to "give up on her," reminding her there was no one in the world who cared anything about her. The staff at the home, after all, were getting paid for spoiling and indulging her but she couldn't stay there forever. It was a short-term home, they said, and they were going to move out of state. Ruthie heard this weekly, for months. She ran away from the home and back to her parents in the midst of this second court action-proof enough for the judge that she could not have been too terribly abused or neglected there. Our own muffled, kindly, generalized for-easy-digestion testimony was processed with help from the defense attorney as liberal softheadedness, and Ruthie was returned to the custody of her parents.

The M.s were generous winners. After the court action, they wrote us a letter "forgiving us" and expressing a benevolent expectation that when our youthful 
naivete had been tempered by the wisdom that comes with age and experience, we would understand how very right they had been.

Our last request for information came when Ruthie was fifteen. She had become a ward of the court because she was "incorrigible" and the court was seeking a placement for her. She would not attend school, was drug addicted, promiscuous, and the veteran of at least one abortion. She had been arrested for shoplifting. At last the $M . s$ had a "diagnosis" they could accept.

Their final letter to us was triumphant in discussing the latest unarguable proof of "bad blood' and innate perversity. They reminded us that they had fought for proper discipline and special schooling for her all along, at great financial and emotional expense. They had done everything humanly possible. All the experts had ever recommended was to allow Ruthie to do as she pleased. We must now accept the guilt for what she had become-hopeless!

There was some indication that the M.s, stabilized by time and retirement, had shifted the focus of their projections from Ruthie to "hippies and yippies" in general, contenting themselves with letters to the editor and right-wing politics that focused on the bad effects of overindulgence of the young. They didn't need Ruthie so much anymore. We have had no requests for information about her in the last two years.

\section{Sam}

Another case focusing on the extracting of confessions of evil intent and behavior will be described briefly, since Ruthie's case may seem in the reading to be more unusual than it really is. Sam's case also illustrates the characteristic search for outside professional corroboration and the coercing of the child to provide evidence that would lead to such corroboration.

Sam's parents presented him for immediate emergency hospitalization following an alleged sexual attack on his seven-year-old sister. Sam was eleven. His mother presented a long bill of complaints, beginning at age three months when "he wouldn't eat right." At seven months: "I know he could crawl but he sat there and screamed, trying to force me to carry him." At seventeen months: "He was able to control bowel and bladder but would purposely soil so I would have to clean him up." When he was three, his mother took him for his first visit to a psychologist to have his "autism" evaluated because "he wouldn't talk." (Professional opinion disconfirmed autism.)

His good school performance from kindergarten on was attributed to a precocious talent for cheating. Mr. and Mrs. $K$. were involved in an altercation with the school because the latter refused to place Sam in a room for the emotionally disturbed. Sam had a history, similar to Ruthie's, of being paraded from one agency to another. Mrs. $K$. further reported that Sam had made two previous attempts to kill his sister, once leaving her alone at a busy intersection at age two, once holding her head under water in a wading pool. Mr. and Mrs. $K$. saw Sam as a criminal and thought he really ought to be in prison or at least in a juvenile detention home. Having delivered themselves of this history-and of Sam-they disappeared except for rare visits and a few letters.

Sam seemed a chilly, withdrawn child, most unwilling to let anyone get close to 
him. Only after a year of hospitalization was he beginning to be able to tolerate warmth, closeness, or any real communication. There were many misgivings expressed about his accessibility to treatment and about the extent of his character pathology. Diagnosis was revised, and Sam's remoteness reassessed as terror and despair, after an observed visit between Sam and his parents.

\section{Making Sam "Confess"}

The parents had requested that their social worker and Sam's primary care worker meet with them and Sam. The parents were upset because hospital staff were not seeing the behavior they saw in Sam. They wanted to prove to the hospital staff that Sam was pulling the wool over their eyes and to demonstrate how one "got the truth out of him." The following is from a staff description of the visit:

The visit began with the parents noticing that five of the seven pairs of pants he had brought with him to the hospital were not in his room, asserting that he had destroyed them out of anger at the parents for sending him to the hospital. They urged him to confess, challenged him to "come up with those pants immediately," threatened physical punishment, and to "put him up against the wall." Ward staff hastily established that the pants were in the laundry while Sam's primary care worker, Frank, restrained Mr. K. from assaulting Sam. Mr. and Mrs. K changed the subject instantly when the staff "came up with the pants."

The K.'s then focused on an incident in which Sam had turned in a key which he had found near the school office. Mrs. K. kept pointing out to Frank [primary care worker] that she was the only one who knew how dangerous Sam was. To demonstrate her ESP powers, she began grilling Sam about finding the key. Sam at first clung to his story, explaining to his parents how he found the key and turned it in. Mrs. K. insisted that Sam was lying, raising her voice and repeating, "Tell us the truth Sam." Sam's response was, "Yes, mother, I am telling the truth." It was apparent that Sam was going to stick to his story. Mr. K. then spoke up to Sam, saying, "If you don't want me to take you down the hall and put you up against the wall, you'd better tell the truth." Sam, tears streaming down his face, said, "Yes, father," but did not confess to taking the key until Mr. K. made a move toward him. Very frightened, Sam then said, "Yes, I took the key." At this point, mother looked at Frank and said, "There you go, Frank, that's how you get the truth out of him."

From this point on, things escalated greatly. Any attempt Frank made to intervene was immediately cut off by both parents who insisted that he observe how they handle Sam in getting at the truth. Mrs. K. would point out to him the signs to look for in Sam, understood by her through ESP. She looked at Sam and pointed out to Frank the look in his eyes. When Frank looked at Sam's eyes and looked back at mother in bafflement, she said, "Watch how they move." She also suggested that Frank look at his throat and see how he swallows. Sam looked very frightened of mother and the possibilities of what might go on. During this course of the conversation, Mr. K. added that Sam is quite afraid of being physically harmed, thus if Frank ever doubted his word in dealing with Sam all he ever had to do, the father said, is put him up against the wall and that would get the truth out of him, for Sam, as the father said, is chicken-shit.

Mother then began highlighting her ESP powers, pointing out how she was able to turn lights off and on, and to levitate things. At this point, her eyes focused on the ice machine and began moving rapidly up and down as if she were really trying to use her powers to move this machine out from the wall. Mother went into a rage about how very sick and evil this boy was, and was quite upset at the fact that none of these symptoms had been seen at $\mathrm{CPH}$, that we had not seen the real Sam.

In similar fashion they extracted confessions about Sam's threatening to kill a girl on the ward. (In fact, he had yelled at her to stop 
pestering him while he was watching telesion.) After Sam confessed to this threatened murder, his father remarked seriously that the kid was a convicted rapist and he probably ought to be in a juvenile detention center somewhere. Sam also was pressed to confess having stolen a magic marker when in fact he had bought it with a staff member in attendance. Mr. K. threatened Sam with, "Do you want me to take you into the bathroom?" moving toward Sam. Sam would then cry and confess in all directions. "Did you steal?" "Yes, mother." "How much?" "A dollar from Frank." "You're lying, how much?" "Maybe it was five dollars."

The visit was terminated early and forcefully by staff, the K.'s objecting and then triumphantly pointing out how Sam had made fools of all of us.

A week later, a summary of contact with the $K$.s by a court social worker reached the hospital through complex channels and after many delays. The court worker had talked with the elusive little sister. The child had been quiet and frightened in her interviews with the social worker and finally burst out crying, "She [mother] kept asking questions and questions and wouldn't stop. We had to say those things. She thought we were lying." The court worker was quite certain that the rape incident had not occurred. We were never able to get a hospital or a physician's report on the "swollen and bruised genital area" described by Mrs. $K$. as having been discovered in a physical examination reportedly done shortly after the alleged rape. In fact there was no report of any examination of Sam's sister in the files at the hospital designated by Mrs. $K$.

A court action involving termination of parental rights is in process at this time and is being contested. The parents wish to remove Sam from the hospital and to "give him another chance" at home.

\section{DISCUSSION}

Since Ruthie and Sam appeared at w. hospital, we have seen similar cases. An eight-year-old girl whose parents were searching for a diagnosis of mental retardation had had her intelligence assessed yearly since age eight months. Our best estimate was that she had become the focus of parental guilt over sexual impulses and practices. She finally did show evidence of severe social retardation, exacerbated by child-rearing practices appropriate for a three-yearold but growth-discouraging for a latency-aged child.

A fifteen-year-old girl, pressured to "confess" to sexual misbehaviors, had been observed, punished, isolated, and lectured to in a way that was highly reminiscent of Ruthie.

Mary-Eva, a six-year-old child of a chronically schizophrenic mother, was "Mary" in periods of remission, "Eva" during psychotic periods. Since infancy, Mary-Eva had been identified as the one who, by her crying, caused Mama to be sick. Older children in the family tried to "drive the devil out of Eva" by physical torture in order to "make Mama well again." This finally precipitated a legal intervention and all five of the children were psychiatrically evaluated. MaryEva's next youngest sibling was diagnosed as having an "interactional psychosis," but Mary-Eva was judged less severely damaged, suffering from low self-esteem and masochism and readily accepting the blame for the family's misfortunes.

In each case, the preoccupation with the child's problem protected a very precarious psychological balance in one or both of the parents. Ruthie and Sam were chosen for description because, when they were presented for treatment 
during latency, they were assessed as intact and healthy children by a wide variety of professionals with different theoretical orientations and from widely differing settings. This represents, we believe, not a deficiency in our assessment techniques but an example of parental pathology projected to a psychotic degree onto a child. In Ruthie's case, as with the child described by Bermann, ${ }^{3}$ we saw, over time, the child conforming to parental expectations despite an original good endowment.

The question of the initial psychological sturdiness in Ruthie and Sam deserves further exploration. Perhaps Ruthie's first four years were more benign than her adoptive parents could ever believe. Perhaps Sam's grandparents, heavily involved in the preschool years, helped him to form a sturdy ego. We cannot know because the only source of such information available to us is the parents, and they are utterly committed to their own need-determined negative perception of the child. We are thus forced to forego history and rely only on the test assessment and interview observations. No evaluation supported an assessment of these children as severely damaged either intrapsychically or in their capacity for social relationships.

Anthony ${ }^{1}$ described cases of folie a deux in which children were co-participants in delusion but not the focus of them. He mentioned, in passing, that some children are able to maintain a "double standard" of reality testing

... conforming to realistic expectations outside of the home while maintaining an irrational orientation within the family circle. The ego's reality testing often clashed with the needs of object relations, the mother frequently making the acceptance of her delusion a test of loyalty. (p. 586)
This seemed to be the case with Ruthie, as evidenced by her "confessions" at age eight. The child's vulnerability, dependency, and suggestibility certainly fulfill the conditions for a "paranoid contagion." The double standard of reality testing may partially explain the parents' outrage at the child's "lying" and "slyness" in presenting herself or himself differently to outsiders than she or he does at home. Anthony also stated that, after separation from the parent, the delusional material evident in the child subsided and disappeared. ${ }^{1}$

Furthermore, professionals who saw the parents separately from the child found them difficult and rigid but not bizarre. Except when she was dealing with Sam, his mother's "ESP" and religious fundamentalism was no more peculiar than that seen in many hysterical women who may be fairly affectionate and effective mothers. Both fathers held responsible minor management positions, and had for many years. One might look at other etiological patterns. Ruthie's parents were elderly, over 50, when we evaluated the family. But when we include them with the whole group of scapegoat children evaluated at court referral because of eventual child abuse, the age-range of the parents in this group is comparable to that of the clinic population as a whole. Ruthie was adopted at age four, but in the total scapegoat group all were natural children except for Ruthie who, by court decision, was judged less badly treated than they. All of these children were singled out early as different and "bad." Adoption, in Ruthie's case, merely furnished another basis for singling her out, making her "different," a need that was characteristic of all these parents. 


\section{CONCLUSIONS}

Parent-child alienation may occur often enough to vivify for us the kinds of questions currently occupying the legal system in its scrutiny of procedures involved in the involuntary commitment of children to residential treatment centers: Do parents always act in the child's best interest? Are parents accurately perceiving the child's nature and behavior? If not, how can we insure ourselves against unwitting complicity in such misperceptions-dependent to the degree that we are on parental observation and report? Even if we correct our own perceptions, is residential treatment a proper step, or does it aggravate the perception of the self as aberrant that has already been grafted onto the relatively healthy ego of the child?

On the other hand, advocating a termination of parental rights arouses an existential anxiety in us. It is a much greater degree of environmental manipulation than we are accustomed to or can easily sustain in secure professional conviction of an ethical stance. We are caught in an ethical dilemma, in that not acting early and promptly to remove a child from a pathogenic, psychotic set of parents bears many risks for our child patient. Acting too early or from insufficient information in such a life-affecting manner is bad practice and uncharacteristic of our generally deliberative profession.

This being so, we must prepare ourselves to more quickly obtain the information we need for decision making. We need to build a professional literature that will help us to identify such families more efficiently and certainlya literature comparable to the "battered child" literature. Those who must make decisions about physical child abuse, now have available contributions $4,7,8$ that help alleviate the sense of isolation and threat affecting the practitioner at such moments.

Finally, we of the mental health profession may come to propose and support our own ideas of necessary modifications of the legal system, rather than leaving the initiative to the courts. We may advocate the abandonment of the current "adversary" position and support instead a form of "no fault divorce" between parents and child when separation seems indicated. Present arrangements often require proof of a criminal degree of abuse or neglect if parents oppose termination of rights. (In a court action involving Mary-Eva, a mistrial was declared because the judge referred to psychological neglect instead of confining the action to consideration of physical neglect.) In cases such as we have described, the parents are already preoccupied with an unconscious burden of guilt and blame, heavy enough to have led to alienation from the child in the first place. Court proceedings that cast parent and child in the position of antagonists, enlisting "experts" to testify publicly as to the inadequacies of both, have the qualities of nightmare for the child and particularly for the parents.

We have described parents who have spent years "defending themselves" from fancied condemnation by the outside world through a desperate insistence that experts see their child "for what he is." They wish to free themselves from unconsciously rooted historical guilt over unacceptable feelings or impulses that they have displaced onto the child. For the parents, the nightmare quality of the court hearing comes from its vivid dramatization of a situation that parents 
and child have played out for years in internal courtrooms, with the unwilling, unwitting partnership of a variety of public institutions.

If separation does not occur, there seems to be a tragic inevitability in the unfolding of their lives. The nightmare continues for the child. As years go by, the child grows more and more to be what the parents perceive him or her to be, as was true with Ruthie-an observation supported by Bermann ${ }^{3}$ and by our work with the other scapegoat groups.

If a decision is made that a child cannot thrive with a given set of parents, other difficulties arise. Judges, lawyers, pediatricians, and mental health professionals suffer conflict and anxiety resulting from rescue fantasies concerning the child on the one hand, and a guilty overidentification with the parents on the other hand. The latter may result from guilt over our own less-than-perfect parenting, but also from a primitive anxiety, present in all of us, about offending powerfully united parent figures. The superego atmosphere of the courtroom most probably exacerbates such anxiety and inhibits the effectiveness of our efforts.

An important resource under such professional psychological stress is the support of peers and of a body of theoretical and practical literature upon which to base opinion and recommendation. This paper has attempted to de- lineate some characteristics of a particular parent-child interaction for which the treatment of choice would include separation-a sad and final "divorce." This is an extreme action, but one that seems necessary if the child is to escape the enactment of a preordained life role as the embodiment of someone else's hated self.

\section{REFERENCES}

1. ANTHONY, E. 1970. The influence of maternal psychosis on children-folie a deux. In Parenthood: Its Psychology and Psychopathology, E. Anthony and T. Benedek, eds. Little, Brown, Boston.

2. BEHRENS, M. AND ACKERMAN, N. 1956. The home visit as an aid in family diagnosis and therapy. Soc. Casewk 37:11-19.

3. BERMANN, E. 1973. Scapegoat: A Study of the Impact of Death Fear on an American Family. University of Michigan Press, Ann Arbor, Mich.

4. HELFER, R. AND KEMPE, C. 1968. The Battered Child. University of Chicago Press, Chicago.

5. HENRY, J. 1972. Pathways to Madness. Random House, New York.

6. JOHNSON, A. AND SZUREK, s. 1952. The genesis of antisocial acting out in children and adults. Psychoanal. Quart. 21:323-343.

7. MILOWE, I. AND LOURIE, R. 1964. The child's role in the battered child syndrome. J. Pediat. 65:1079-1081.

8. STeEle, B. 1970. Parental abuse of infants and small children. In Parenthood: Its Psychology, E. Anthony and T. Benedek, eds. Little, Brown, Boston.

9. TOOLEY, K. 1975. The choice of a surviving sibling as scapegoat in some cases of maternal bereavement. J. Child Psychol. Psychiat. 16:331-339. 